\title{
Swan Ganz Catheter
}

National Cancer Institute

\section{Source}

National Cancer Institute. Swan Ganz Catheter. NCI Thesaurus. Code C122613.

A hollow tube with a balloon or sail tip that is advanced into the pulmonary artery to

measure right heart pressure and cardiac output, and enable mixed venous blood sampling. 